\title{
The Cutting Edge
}

\section{THE NATIONAL NETWORK OF DEPRESSION CENTERS: PROGRESS THROUGH PARTNERSHIP}

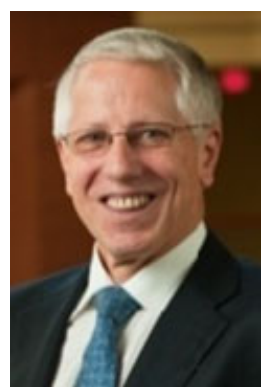

John F. Greden, M.D., is the Executive Director of the University of Michigan Comprehensive Depression Center and Founder and Chair of the National Network of Depression Centers (NNDC). His academic activities include 28 years of NIH-funded projects studying major depressions and bipolar disorders, emphasizing biomarker and clinical correlates of depression and bipolar disorders over a patient's lifetime. These include hypothalamic-pituitary-adrenal (HPA), neuroimmune, sleep laboratory, and psychomotor measures; causes and interventions for Treatment Resistant Depression (TRD); and prevention of depressive recurrences. He served 22 years as Chair of the University of Michigan Department of Psychiatry, is the author or coauthor of 265 peer-reviewed publications or books, has given approximately 410 invited presentations, supervised 14 NIH "K" and Veterans Administration Career Development young investigator awardees, and continually seeks to promote translational themes to educate a new generation of clinical investigators. He served as Past President of the Society of Biological Psychiatry and the Psychiatric Research Society and as a Co-Editor of the Journal of Psychiatric Research for 7 years. In 2001, he founded and still directs the University of Michigan Comprehensive Depression Center, patterned after the nation's Cancer Centers. In 2007, he led formation of the NNDC, which currently includes 22 of the nation's leading academic medical centers and is the focus of this article.

\section{THE CHALLENGE}

The time has come to meaningfully transform our nation's strategies for counteracting the scourges of depressive and bipolar illnesses.

Hundreds of excellent studies confirm that major depressive disorders, bipolar illnesses, and related disorders afflict an estimated one of every five Americans, lead the United States and the world in disease burden and disability, and account for more than 30,000 U.S. citizens' deaths annually by suicide while thousands more die earlier because of associated medical consequences. Mood disorders are second in contributing to America's health costs, trailing only cardiovascular diseases. ${ }^{[1-6]}$ Hundreds of additional studies provide substantial understanding of why these disorders produce such huge burdens (Table 1). It is reasonable to conclude we have thoroughly identified the challenges associated with the prevalence, burdens, disabilities and costs of depressions, and bipolar illnesses. It is time to prioritize solutions.

\section{SOLUTION: A NATIONAL NETWORK OF DEPRESSION CENTERS}

The time has come to fight depression and bipolar illnesses by adapting network and data sharing strategies previously shown to be successful for other chronic disorders and to implement a vision that enables every resident in the United States to be within 200 miles of the expertise needed to better diagnose, treat, and prevent clinical depression and bipolar illnesses. The foundation for such an effort is underway via the recently established National Network of Depression Centers (NNDC), patterned after the nation's networks of cancer centers. This article will describe the National Network of Depression Centers www.NNDC.org, its origins, progress to date, and the academic, federal, community, and corporate partnerships that are either developed or still required.

\section{WHY THE NEED FOR A NETWORK?}

Despite years of growth in research dollars for neuroscience and mental health, breakthroughs for those brain disorders producing depression, bipolar illnesses, and related conditions have been sparse and global progress may be stalled even more because of growing economic constraints. ${ }^{[7]}$ Other contributing reasons are obvious and arguably would be improved using the power of networks and partnerships. ${ }^{[8-10]}$ First, mental health investigators and clinicians have not adopted a common language for characterizing and monitoring clinical severity and outcomes, have not adopted standardized "vital signs" for mood disorders comparable to blood pressure readings for hypertension, and have not routinely employed measurementbased care despite evidence that it improves outcomes. Network adoption of a "common language" will accelerate the improvements being sought.

\footnotetext{
*Correspondence to: John F. Greden, Rachel Upjohn Professor of Psychiatry and Clinical Neurosciences, University of Michigan Medical Center, 4250 Plymouth Road, Ann Arbor, Ml 48109. E-mail: gredenj@med.umich.edu

DOI 10.1002/da.20862

Published online in Wiley Online Library (wileyonlinelibrary.com).
} 
TABLE 1. Contributors to huge global burden of disease for major depressive disorders and bipolar illnesses

1. High prevalence and peak symptom onset during ages 15-24

2. Persistent stigma

3. Under-diagnosis, under-treatment, inappropriate treatment, or no treatment for millions

4. Complex gene-environment underpinnings that have thus far eluded translation into treatments

5. Unavoidable stressors precipitating or exacerbating episodes

6. Current "first-line" treatments that do not routinely achieve clinical remission; an episodic, recurrent, usually lifetime pattern that worsens and becomes more treatment resistant and chronic; possible cumulative alterations in brain gene expression, neurotrophins, circuitry, and morphology

7. Development of Treatment-Resistant Depression (TRD) for approximately one-third of the millions with mood disorders

8. Relatively infrequent use of effective, long-term maintenance treatments despite their value in preventing prevent recurrences

9. Few large-sample studies of biomarkers and outcomes, leading to absence of personalized treatments; and;

10. Apparent de-emphasis of industry efforts to produce more effective, safer antidepressant or mood-stabilizing medications

Second, mental health literature is replete with clinical trials characterized by small numbers, ranging from 40 to 70. In comparison, cancer, cardiovascular, and diabetes chronic care specialists, utilizing established, financially supported, large and ongoing network collaborations, long ago moved to multi-site, standardized, longitudinal studies of thousands or tens of thousands to address vitally important clinical questions that characterize chronic disorders, such as whether antidepressant medications reduce or accentuate suicide risk. ${ }^{[5]}$ When studying complex genetic diseases with multiple etiologies or searching for biomarkers, small samples are antithetical to adequate statistical power. Networks are necessary to substantially counteract that shortfall.

Third, the focus of these research studies needs to be shifted to a lifetime perspective. Depression and bipolar disorders are long-term and chronic in their course while our study strategies are short-term and acute. While arrays of successful "mini-networks" have been established, almost always supported by grant projects with a sundown clause, the real need is sustainability to assess longitudinal course and maintenance of stability, comparable to diabetes mellitus. During the past decade, $\mathrm{NIH}$-funded clinical trials that became well-known by their acronyms such as STAR $* \mathrm{D}$, TADS, TORDIA, STEP-BD, and others ${ }^{[1,12]}$ have been successful in generating useful information but frustrating in not producing translational breakthroughs that attain and maintain wellness. ${ }^{[13,14]}$ Filling these voids is essential. Mini-network launches require considerable money, months, or years and just when each has matured enough to enroll and retain a cadre of research participants and investigators, it tends to be disbanded. Articles appear; clinical breakthroughs remain elusive.

These problems are neither new nor unique to brain research and mental health, ${ }^{[8]}$ but other fields have moved more rapidly to adopt network solutions. The void in mental health fields at least partially explains why Unutzer ${ }^{[14]}$ concluded in 2009 that over the past decade "epidemiological research on the prevalence of depressive and anxiety disorders does not show any substantial reductions in the population-level burden of these illnesses."

\section{IMPROVING OUTCOMES BY EMULATING OTHER SUCCESSFUL NETWORKS}

Other chronic disease specialties have addressed translational network shortcomings by establishing and relying upon academic-private-community-federal collaborations. For these to function effectively, a federal component is generally required. The National Cancer Institute (NCI) Network serves as perhaps the bestknown prototype. This network is credited with improving outcomes for those with cancer, in some cases dramatically. ${ }^{[15]}$ In 1954, childhood leukemia victims survived an average of only months. Now, aided by translational advances developed by and disseminated through NCI-supported comprehensive cancer center faculty and staff members, more than $80 \%$ are cured. The Director of the National Cancer Institute (NCI) in 2006 stated that "The cancer centers have been and continue to be the crown jewels of the NCI's program." ${ }^{[16]}$ Large samples are their norm. Cancer stigma concomitantly has been remarkably reduced. Whispered references to "The Big ' $C$ '” were once the cultural perspective. No longer. The United States now has more than 70 Cancer Centers across the country proudly displaying their names, accomplishments, and philanthropic gains. Cardiovascular Centers of Excellence similarly have aided an approximate $50 \%$ reduction of death rates from heart disease over the past 40 years. Partially motivated by all these reasons, leaders in counteracting other chronic illnesses, such as autism, Parkinson's disease, and Alzheimer's disease, have learned the power of sustainable networks.

Over the same span of decades, depressive and bipolar illnesses-statistically more burdensome and expensive than cancers ${ }^{[17]}$ remained relatively hidden, secreted away, and out of the mainstream while suicide rates, most associated with depression and bipolar illnesses, experienced no significant decrease. [5] It should not be overlooked that funding growth for cancer has greatly exceeded that for mental health research despite depression's burden by itself exceeding those for cancers; collective voices are more often heard. A new model is needed-a network model already proven to work and to focus greater attention and resources on these most-burdensome of diseases.

\section{WHAT IS A COMPREHENSIVE DEPRESSION CENTER?}

The formation of the NNDC is predicated upon the existence of individual centers of excellence for depres- 
sion, bipolar illness, and related conditions that are coupled with commitments to advance and disseminate knowledge. In 2001, the Board of Regents of the University of Michigan approved a proposal to establish presumably the first large-scale Comprehensive Depression Center, patterned after the nation's Cancer Centers. The original fivefold Mission remains: (1) Find depressive and bipolar illnesses earlier in life by implementing cost-effective widespread preventionoriented screening; during ages of peak onsets; ${ }^{[18]}$ (2) Treat earlier when most treatable and attain the ever-important recovery; ${ }^{[19]}$ (3) Prevent recurrences and maintain wellness; while primary prevention remains a vision, secondary prevention of depressive episodes is effective but inadequately prescribed; ${ }^{[20-22]}$ (4) Counteract stigma, an essential mission if other aims are to be achieved; ${ }^{[23]}$ and (5) Transform public policy, ${ }^{[24]}$ starting with catalyzing a national network of depression centers patterned after the nation's network of cancer centers. This fifth goal is the primary focus of this article.

A comprehensive center denotes a virtual home base dedicated to the integration and subsequent dissemination of research, clinical care, education, and public policy. Comprehensive networking implies interdisciplinary collaboration, standardization, data sharing, lifetime perspectives, and a dedication to tackling and translating truly important, unanswered clinical challenges. It supports infrastructure venues that enable basic science investigators and their clinical colleagues to readily partner, plan, test, continually improve, export and sustain translational strategies. and export translational strategies. "Comprehensive" creates an expectation that the search for new knowledge is incomplete until disseminated and implemented in primary care and community settings where most mental health problems are treated; and that prevention programs deserve an equal seat at the research and clinical tables. Perhaps, most pivotal and admittedly difficult to achieve with traditional well-established departmental structures that segment by age, "comprehensive" mandates efforts to understand and integrate efforts across the lifespan, extending from perinatal through elderly, again similar to lifetime clinical efforts to manage diabetes mellitus. Public health and self-management principles are valued, emphasized, taught, measured, and steadily improved. For obvious practical reasons, Comprehensive Depression Centers, similar to Cancer Centers, rely upon a firm, sustainable infrastructure that does not require expensive rebuilding after completion of each project. Education of providers, the public, third-party payers, and a new generation of interdisciplinary scholars is recognized as essential. And collaboration with public policy leaders is perceived as essential and laudable.

"Comprehensive" further denotes the antithesis of "silo," a colloquial and pejorative term for working in isolation. A "network of centers" does not, however, denote an expectation that every struggling patient or family member should travel to some distant "Ivory
Tower." Rather, the expectation is that knowledge, treatments, and preventive practices emanating from these Centers will be more rapidly disseminated and imbedded into the front-lines of health care.

Adapting NIH-NCI principles, in 2001 the University of Michigan Depression Center was strategically proposed to be interdisciplinary and broadly based. It was designed to serve as a focal point for collaboration for more than 150 depression and bipolar faculty members and trainees from 33 departments and 13 of the University's schools, colleges and institutes, and promote integration in new studies, community outreach, clinical delivery, evidencebased education, stigma reduction, and public policy. The Center is administratively housed in the Department of Psychiatry. Initial financial support was blended from the University, a National Institute of Health (NIH)-National Center for Research Resources (NIH-NCRR) grant of $\$ 4$ million, the Department of Psychiatry,, and approximately $\$ 15$ million from donors (these indispensible development dollars have since expanded three-fold). Such combined support enabled construction of an innovative and attractive research and clinical facility - the "antithesis of depression"- that opened in 2006 and serves as the physical hub from which an array of "virtual" studies and projects are coordinated. The facility, also housing ambulatory psychiatry programs, is a tremendous boon but not the indispensible component. Rather, patients, families, faculty, staff, community volunteers, friends, collaborators, and supporters are the core of any Center. To help overcome stigma, the University of Michigan "Depression Center" proudly acknowledges its name.

\section{TRANSITION TO A NATIONAL NETWORK}

The Michigan Depression Center's original mission emphasized that one Depression Center is not enough to address national data-sharing needs. It is recognized that an integrated national network was required, tying Centers of Excellence together with satellite clinics, community partnerships, imbedding strategies, care managers and outreach programs such as telehealth. Only then will essential data be generated and translated to advance diagnosis and treatment, refine health delivery systems, deliver better care at manageable cost to the vast number of untreated and underserved populations, and meaningfully address preventive strategies. ${ }^{[25]}$

In 2007, following encouragement by members of the University of Michigan Depression Center's National Advisory Board, invitations to participate in launching the NNDC were extended. In 2008, an inaugural meeting was held at the University of Michigan Depression Center. Aided by indispensable support from students and faculty at the Ross School of Business at the University of Michigan throughout 2008, representatives from 16 founding member institutions drafted and adopted a charter (www.NNDC.org). Requirements for participating Centers are summarized in Table 2. 
TABLE 2. Criteria for individual centers of excellence in the national network of depression centers (February 2011)

1. A critical mass of interdisciplinary experts in depressive and bipolar disorders

2. Formally establishing a Depression Center that integrates basic, translational, clinical, and population-based research with clinical and educational dissemination and outreach strategies;

3. Interdisciplinary participation from diverse schools and departments within respective academic institutions, such as psychiatry, psychology, family medicine, obstetrics, pediatrics, college student health, schools of public health, nursing, pharmacy, social work, and others;

4. A large grant funding base focusing on depression, bipolar and related conditions;

5. A dedication to translation of new findings to clinical delivery venues;

6. Substantial institutional commitment in the form of space, resources, and authority provided to Center operations and the Director;

7. Community outreach, education, and training activities with special efforts to reach underserved, rural, and neglected populations;

8. Commitment to support and participate in national network collaborations with other Centers and other agencies ("playing well together in the sandbox")

Twenty-one academic universities (Table 3 and Fig. 1) currently belong to the NNDC. Annual growth is underway. Global federations or networks are being discussed.

\section{INITIAL AIMS OF THE NNDC}

Selected initial aims for the NNDC included (1) investigating important, unanswered research translational questions through establishment of outreach partnerships with primary care and specialties at highrisk for mood disorders; (2) developing and routinely using a common clinical language and standardized outcome measures; (3) creating large research registries and "truly large" standardized data bases; (4) screening early and promoting a lifelong perspective for these chronic diseases; (5) developing and testing biomarkers and the new and improved treatments that we so sorely need; (6) collaborating with advocacy groups and others to counteract stigma; (7) developing and disseminating real-time disease guidelines; and (8) emphasizing programs to maintain recovery and wellness. NNDC members concluded early that the network must "partner, share and leverage" its talents, expertise, organizational stability, and resources with those of others, notably striving to work with NIMH and other NIH Institutes, SAMHSA, CTSAs, Agency for Health Research Quality (AHRQ), VAH, DOD, Foundations, and potential corporate partners. Network collaborations may help overcome seemingly insurmountable obstacles by studying drug, neuromodulation, psychotherapy and other combinations from the inception of treatment to "attack the disease on multiple fronts," comparable to the strategies used for HIV and currently being assessed for cancer. As Paoletti was recently quoted as stating (26) when describing pharmaceutical efforts to use drug combinations at earlier stages, "You don't kill cancer in only one way." The same may prevail for depression,
TABLE 3. Members of the national network of depression centers (February, 2011)

1. Brigham \& Women's Hospital, Partners HealthCare-Harvard Medical School

2. Columbia University

3. Duke University

4. Emory University

5. Johns Hopkins University

6. Massachusetts General Hospital, Partners HealthCare-Harvard Medical School

7. Mayo Clinic

8. McLean Hospital, Partners HealthCare-Harvard Medical School

9. Medical University of South Carolina

10. Stanford University

11. University of California, San Francisco

12. University of Cincinnati \& Lindner Center of HOPE

13. University of Colorado

14. Universwity of Illinois-Chicago

15. University of Iowa

16. University of Louisville

17. University of Massachusetts

18. University of Michigan

19. University of Pennsylvania

20. University of Texas Southwestern

21. Weill Cornell Medical College

since fewer than $40 \%$ attain wellness using traditional treatment approaches for the first episode (11).

These aims are extensive-intentionally so. Some health networks or societies devote their efforts to one or two "legs of a table," such as research and advocacy. NNDC inaugural members concurred that by leveraging their existing strengths, an integrated approach could and should incorporate four legs-research, clinical translation, education, and public policy.

\section{SELECTED NNDC ACCOMPLISHMENTS TO DATE}

In the first year, four Domain Committees (Research, Clinical, Educational, and Public Policy) and initial Task Groups were formed. The several hundred leaders and members of the NNDC-steadily growing-have been remarkably generous of time and commitment. A difficult but critical first step was taken in 2009-2010 with adoption of a standardized assessment package, the common language or "vital signs" of mental health, followed by establishment of a Data Coordinating Center, formed with guidance and participation of a Clinical Translational Science Award (CTSA) team in one University. Growth in the integrated data pool is now underway. Partnerships with such federal agencies on local and national levels arguably are a necessary prototype for the future.

The hundreds of faculty and staff from NNDC member sites are currently collaborating in Task Groups to address initial aims. Twelve are now underway. Examples include Women and Mood, evaluating depression during pregnancy, postpartum 


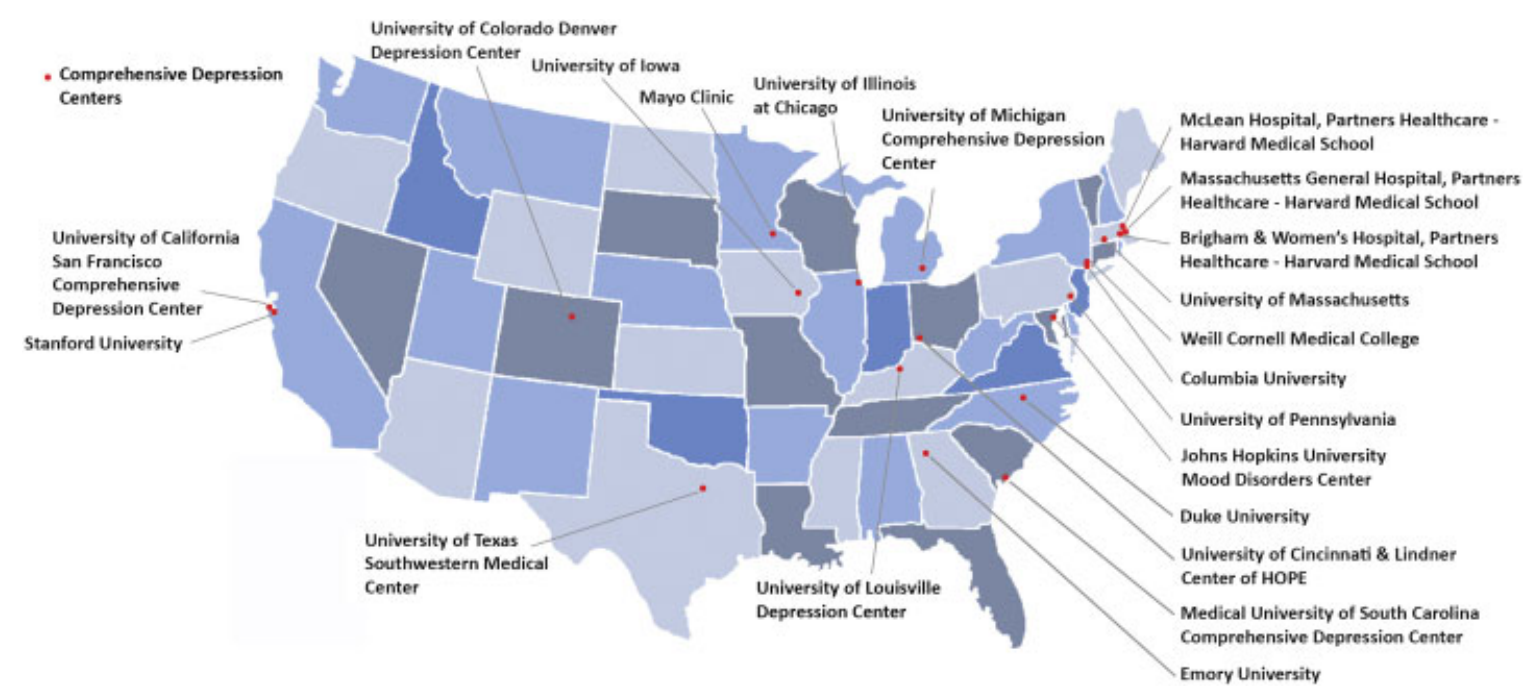

Figure 1. Map of the United States illustrating current locations of centers in the NNDC, National Network of Depression Centers.

period, and perinatal mood disturbances and using an emergent registry for ongoing studies; Bipolar disorders, with many of the sites collaborating with the Prechter Bipolar Genetic Repository and with NIMH support and other NNDC colleagues, emphasizing longitudinal outcome biomarkers; Neuromodulation for Treatment-Resistant Depressions (Electroconvulsive Therapy [ECT] and Transcranial Magnetic Stimulation; Geriatric Mood Disorders; Mood disorders screening and suicide prevention in schools; College Mental Health; Intervention Dissemination and Health Services; Military, Veterans and Families. Other Task Groups to be launched in the near future include Child and Adolescent Mood Disorders and Telehealth. An NNDC scientific Journal is being discussed.

The Educational Domain Committee Task Groups include: (1) "MoodBook," a comprehensive, web-based clearinghouse for Mood Disorders compiling and organizing the preeminent information to improve quality, trustworthiness, and availability for consumers and clinicians; (2) Adolescent Depression Awareness Program (ADAP), a School and Community Depression Prevention developed at Johns Hopkins and being disseminated among a growing number sites; and (3) College Mental Health Task Group.

To aid in transforming public policy, in late 2009, the Public Policy Domain Committee completed a "white paper" requested by a U.S. Senator about the lifesaving and cost-saving potential of a network. Various NNDC leaders provided requested consultation to those writing subsequent legislation. The result was the ENHANCED Act (Establishing a National HealthAdvancing Network of Centers of Excellence for Depression), passed as part of the Patient Protection and Affordability Act. Funding was projected to be distributed via SAMHSA programs but has not yet been finalized.

These initiatives were launched in the NNDC's first inaugural years; much more remains to be done.

\section{MOTIVATIONS FOR NNDC PARTICIPATION}

What motivates NNDC participation? Member feedback indicates an altruistic conviction that a sustainable network may be the only workable and affordable solution to overcoming current small sample sizes, research shortcomings, barriers in clinical translation, and development of improved treatments ${ }^{[2,27]}$ The NNDC is perceived by many as already helping catalyze stigma reduction in their home communities, enhancing local research prowess and funding, recruiting a new generation of stellar trainees, young investigators, and faculty members, and becoming part of a strong, evidence-based "voice." The promise of entrepreneurial opportunities and philanthropic support are additional magnets. In communities with developing Depression Centers, there is a palpable willingness to provide financial support to help attack depression and bipolar illnesses among a growing number of affected families and while total reliance on this approach delays attainment of the important aims, combining and leveraging academic, federal, community, and philanthropic support is a proven model for funding biomedical breakthroughs.

\section{A VISION OF SUSTAINABLITY}

Ongoing integration of research, clinical translation, education, and public policy can only occur when coupled with sustainability to attain and maintain public health gains. Sustainability initially depends upon endorsement by University leaders; an effective strategic plan; the successful collection and integration of data that can be used to address important questions; interdisciplinary participation in research grants; scientific publications; communication of positive accomplishments; and a solid financial infrastructure. The latter will rely upon an array of partnerships, including patients, families, university schools and departments, foundations, corporations, 
donors, advocacy groups, community groups, donors, and federal agencies. The latter are demonstrated as vital components for sustainability of other networks.

The NNDC's aims are synergistic with those of federal agencies and other entities invested in improving our healthcare system. NNDC centers hold unique capacity to leverage the aims of others and be a "forcemultiplier." Following the policies of each agency, the Network aims to compete for, propose, and respond to research and service opportunities. National Institute of Health (NIH) and Agency for Health Research Quality (AHRQ) collaborations would help build and support the integrated and sustainable research foundations that are currently benefitting cancer, Alzheimer's, Autism Spectrum Disorders, and others. NIMH support of sustainable networks may be especially essential. SAMHSA funding, such as authorized in the ENHANCED Act, would enable dissemination to economically and geographically underserved populations and aid such vital efforts as suicide prevention and services for returning veterans and families, especially "citizen soldiers" in the National Guard and Reserves (more than $40 \%$ of deployed troops), since most return to scattered parts of the country and not to military bases where medical care is readily available; partnerships with other SAMHSA networks are also likely to produce incremental gains and cost efficiencies; ${ }^{[28]}$ CTSA partnerships would accelerate translation and training. VAH and DOD partnerships would further enable assessments and service delivery for returning veteran populations.

These and other convictions at least partially explain why participating NNDC Centers, lacking other sources of financial support, have endorsed long-range perspectives and despite financial struggles, agree to pay annual dues to enable network development. Departments of Psychiatry, traditionally cash-constrained, remain the major sources of such dues, partially supported in some Centers by other departments, Dean's offices, or donors. However, to achieve the progress needed, many more of the above mentioned supporting partnerships are needed.

\section{SUMMARY}

America's residents and those of the entire world desperately need better strategies to attack depression and bipolar illnesses. A national network of centers of excellence with dissemination are models proven to have profoundly beneficial medical and economic advantages for other chronic diseases. Meaningful progress will only occur through such partnerships because they alone will address existing barriers. The NNDC was started to aid in this effort to attack depressions, bipolar illnesses, and related mood disorders (www.NNDC.org). To attain sustainability and win the fight against depressions and bipolar disorders, this new model requires support.

Acknowledgments. Planning and development of the University of Michigan Comprehensive Depression Center and the National Network of Depression
Centers have been made possible only because of altruistic and expert contributions provided by hundreds of colleagues - too many to mention. However, a number of individuals must be acknowledged:

Huda Akil, Ph.D., University of Michigan; Martha Bruce, Ph.D., M.P.H., Weill Cornell Medical College; Gail Campanella, M.B.A., University of Michigan; William Coryell, M.D., University of Iowa; W. Edward Craighead, Ph.D., Emory University; Gregory Dalack, M.D., University of Michigan; Frank V. deGruy III, M.D., M.S.F.M., University of Colorado, Denver Depression Center; Patricia J. Deldin, Ph.D., University of Michigan; J. Raymond DePaulo, Jr, M.D., Johns Hopkins University; Stuart J. Eisendrath, M.D., University of California, San Francisco Depression Center; Graham J. Emslie, M.D., University of Texas Southwestern; Dwight L. Evans, M.D., University of Pennsylvania; Maurizio Fava, M.D., Massachusetts General Hospital; Mark A. Frye, MD, Mayo Clinic; Kay Redfield Jamison, Ph.D., Johns Hopkins University; David J. Katzelnick, MD, Mayo Clinic; Paul E. Keck, Jr., M.D., University of Cincinnati \& Lindner Center of HOPE; Terence Ketter, M.D., Stanford University; James H. Kocsis, M.D., Weill Cornell Medical College; Anand Kumar, MD, University of Illinois at Chicago; Sarah H. Lisanby, M.D., Duke University; J. John Mann, M.D., Columbia University; Helen Mayberg, M.D., FRCPC, Emory University; Melvin G. McInnis, M.D., University of Michigan Depression Center; J. Craig Nelson, M.D., University of California, San Francisco Depression Center, Maria Oquendo, M.D., Columbia University; Ghanshyam N. Pandey, PhD, University of Illinois at Chicago; Scott L. Rauch, M.D., McLean Hospital; Michelle Riba, M.D., University of Michigan; Anthony J. Rothschild, MD, University of Massachusetts; Alan F. Schatzberg, M.D., Stanford University; Thomas Schwenk, M.D., University of Michigan (University of Nevada in 2011); David Silbersweig, M.D., Brigham \& Women's Hospital; David C. Steffens, M.D., M.HSc., Duke University; Stephen M. Strakowski, M.D., University of Cincinnati \& Lindner Center of HOPE; Allan Tasman, M.D., University of Louisville; Stephan Taylor, M.D., University of Michigan Michael E. Thase, M.D., University of Pennsylvania; Marshall Thomas, M.D., University of Colorado, Denver Depression Center; Madhukar H. Trivedi, M.D., University of Texas Southwestern; Carolyn Turvey, Ph.D., University of Iowa; Thomas Uhde, MD, Medical University of South Carolina Comprehensive Depression Center; Sandra J. Weiss, Ph.D., DNSc, University of California, San Francisco Depression Center; Jesse H. Wright, M.D., Ph.D., University of Louisville; Douglas M. Ziedonis, MD, MPH, University of Massachusetts, and the entire NNDC staff. Special acknowledgements must be provided to the Prechter family for helping launch the concept and initiating as well as continually supporting research at the Heinz C. Prechter Bipolar Research Fund; Mary 
and Ed Meader for supporting establishment of the prototype Michigan Center, and Mr. George Wiegers for supporting development of the network. Their magnanimous contributions are destined to broaden treatment delivery and save lives.

Disclosure: Dr. Greden does not participate in Speakers' Bureaus nor does he hold any corporate contracts or hold stock with pharmaceutical or Biotech companies. He serves on scientific advisory boards for Eli Lilly and Co., Neuronetics, and Merck Pharmaceuticals. He volunteers in a pro bono advisory board capacity for the DBSA (Depression and Bipolar Support Alliance) and the Informed Medical Decision Making Foundation, and as aVice President of the American Foundation for Suicide Prevention (AFSP). He has no conflicting Stock Holdings.

\section{REFERENCES}

1. Kessler RC, Chiu WT, Demler O, Walters EE. Prevalence, severity and comorbidity of twelve-month DSM-IV disorders in the National Comorbidity Survey Replication (NCS-R). Arch Gen Psychiatry 2005;62:617-627.

2. Greden JF. The burden of disease for treatment-resistant depression. J Clin Psychiatry 2001;16:26-31.

3. Lopez AD, Mathers CD, Ezzati M, Jamison DT, Murray CJ. Global and regional burden of disease and risk factors, 2001: systematic analysis of population health data. Lancet 2006;367: $1747-1757$.

4. World Health Organization: The Global Burden of Disease 2004 Update. 2008. Available at: http://www.who.int/healthinfo/ global_burden_disease/en. Accessed September 16, 2010.

5. Gibbons RD, Hur K, Bhaumik DK, Mann JJ. The relationship between antidepressant medication use and rate of suicide. Arch Gen Psychiatry 2005;62:165-172.

6. Greden JF, Riba M, McInnis, editors. Treatment Resistant Depression: A Roadmap for Effective Treatment (Review of Psychiatry Series; Oldham JM and Riba MB, series, editors). Washington, DC: American Psychiatric Press; 2011.

7. Amara SG, Grillner S, Insel T, Nutt D, Tsumoto T. Neuroscience in recession? Nat Rev Neurosci 2011;12:297-302.

8. Crowley Jr WF, Sherwood L, Salber P, Scheinberg D, Slavkin H, Tilson H, Reece EA, Catanese V, Johnson SB, Dobs A, Genel M, Korm A, Reame N, Bonow R, Grebb J, Rimoin D. Clinical research in the United States at a crossroads: proposal for a novel public-private partnership to establish a national clinical research enterprise. J Am Med Assoc 2004;291:1120-1126.

9. Andrews G, Issakidis C, Sanderson K, Corry J, Lapsley H. Utilising survey data to inform public policy: comparison of the cost-effectiveness of treatment of ten mental disorders. British Journal of Psychiatry 2004;184:526-533.

10. Katon WJ. Collaborative care: evidence-based models that improve primary care depressive outcomes. CNS Spectr 2009;14:10-14.

11. Trivedi MH, Rush AJ, Wisniewski SR, Nierenberg AA, Warden D, Ritz L, Norquist G, Howland RH, Lebowitz B, McGrath PJ, Shores-Wilson K, Biggs MM, Balasubramani GK, Fava M. Evaluation of outcomes with citalpopram for depression using measurement-based care in STAR $* \mathrm{D}$ : implications for clinical practice. Am J Psychiatry 2006;163:28-40.

12. March J, Silva S, Petrycki S, Curry J, Wells K, Fairbank J, Burns B, Domino M, McNulty S Clinical Coordinating Center, Duke Clinical Research Institute, Duke University Medical Center,
Vitiello B, Severe J, NIH. Fluoxetine, cognitive-behavioral therapy, and their combination for adolescents with depression. Treatment for Adolescent Depression Study (TADS) randomized controlled trial. J Am Med Assoc 2004;292:807-820.

13. Insel TR, Wang PS. The STAR $* D$ trial: revealing the need for better treatments. Psychiatr Serv 2009;60:1466-1467.

14. Unutzer J. Evidence-based treatments for anxiety and depression: lost in translation. Depress Anxiety 2008;25:726-729.

15. American Cancer Society. Cancer Facts \& Figures 2010, Estimated New Cancer Cases and Deaths by State, US, Atlanta, GA: American Cancer Society; 2010, p4. Retrieved May 26, 2011 from http:// www.cancer.org/acs/groups/content/@epidemiologysurveilance/ documents/document/acspc-026238.pdf

16. "Cancer Institute's New Chief Talks of Cutbacks." New York Times August 17, 2006.

17. Horner MJ, Ries LAG, Krapcho M, Mariotto A, Miller BA, Feuer EJ, Clegg L, Eisner MP, Horner MJ, Howlader N, Hayat M, Hankey BF, Edwards BK. (eds). Surveillance epidemiology and end results (SEER) cancer statistics review 1975-2006, http://seer.cancer.gov/csr/1975_2006/, based on November 2008 SEER data submission, posted to the SEER web site, 2009. Table 2.18: "Estimated United States Cancer Prevalence Counts on January 1, 2006", All Cancer Sites (Invasive): prevalence within past 5 years. National Cancer Institute. Bethesda, MD

18. Zisook S, Lesser I, Stewart JW, Wisniewski SR, Balasubramani GK, Fava M, Gilmer WS, Dresselhaus TR, Thase ME, Nierenberg AA, Trivedi MH, Rush AJ. Effect of age at onset on the course of major depressive disorder. Am J Psychiatry 2007; 164:1539-1546.

19. Judd LL, Paulus MJ, Schettler PJ, Akiskal HS, Endicott J, Leon AC, Maser JD, Mueller T, Solomon DA, Keller MB. Does incomplete recovery from first lifetime major depressive episode herald a chronic course of illness? Am J Psychiatry 2000;157:1501-1504.

20. Greden JF, editor. Treatment of recurrent depression (Review of Psychiatry Series Vol 20; Oldham JM, Riba MB, editors). Washington, DC: American Psychiatric Press; 2001.

21. Geddes JR, Carney SM, Davies C, Furukawa TA, Kupfer DJ, Frank E, Goodwin GM. Relapse prevention with antidepressant drug treatment in depressive disorders: a systematic review. Lancet 2003;361:653-661.

22. Reynolds CF, Dew MA, Pollock BG, Mulsant BH, Frank E, Miller MD, Houck PR, Mazumdar S, Butters MA, Stack JA, Schlernitzauer MA, Whyte EM, Gildengers A, Karp J, Lenze E, Szanto K, Bensasi S, Kupfer DJ. Maintenance treatment of major depression in old age. N Engl J Med 2006;354:1130-1138.

23. Golberstein E, Eisenberg D, Gollust SE. Perceived stigma and mental health care seeking. Psychiatr Serv 2008;59:392-399.

24. Berwick DM. Disseminating innovations in health care. J Am Med Assoc 2003;289:1969-1975.

25. Cuijpers P, van SA, Smit F, Mihalopoulos C, Beekman A. Preventing the onset of depressive disorders: a meta-analytic review of psychological interventions. Am J Psychiatry 2008;165: 1272-1280.

26. Goodman WK, Insel TR. Deep brain stimulation in psychiatry: concentrating on the road ahead. Biol Psychiatry 2009;65: 263-266.

27. Mathew SJ, Manji HK, Charney DS. Novel drugs and therapeutic targets for severe mood disorders. Neuropsychopharmacology 2008;33:2080-2092.

28. National Child Traumatic Stress Network (NCTSN). The NCTSN mission and vision. Retrieved July 10, 2009, from http://www.nctsnet.org/nccts/nav.do?pid = abt_mv 